\title{
IMPACTOS AMBIENTAIS EM ÁREAS URBANAS DA CIDADE DE ILHÉUS: UMA RELAÇÃO ENTRE DADOS PLUVIOMÉTRICOS, MOVIMENTOS DE MASSA E SUBMORADIAS
}

\author{
Lucas Rosário Santos ${ }^{(\mathrm{a})}$ Baitz, Ednice de Oliveira Fontes Baitz ${ }^{(\mathrm{b})}$
}

\author{
(a) Discente do curso de Bacharelado em Geografia, Universidade Estadual de Santa Cruz, \\ lucasrosario.geo@gmail.com \\ (b) Prof. Titular do Departamento de Ciências Agrárias e Ambientais, Universidade Estadual de Santa Cruz, \\ ednice@uesc.br
}

Eixo: Geografia Física e Desastres Naturais

\begin{abstract}
Resumo
A ocupação dessas encostas em Ilhéus ocasiona um grande problema no contexto sócioeconômico, pois o uso e ocupação destes territórios sucedem-se de forma irregular, fora dos padrões de segurança que garantam a apropriação pelo homem, sem que haja riscos físicos e sociais, podendo levar até a perda de vidas humanas. Assim, há diversas áreas de risco em ilhéus, mas a área de estudo deste trabalho busca analisar apenas três bairros Amparo, Conquista e Teotônio Vilela. A metodologia da pesquisa foi dividida em três (3) fazes a primeira fase foi realizado levantamento e analise documental em gabinete, na segunda fase realizamos o trabalho de campo com visitas aos bairros nos quais foram preenchidas as fichas de observação para caracterizar as área e correlacionar com o índice de precipitação, visando a identificação do grau de riscos de ocupação dos bairros citados. Desta forma, concluímos que os movimentos de massa e as enchentes são deflagrados a partir $45 \mathrm{~mm}$ de chuva, por isso é de extrema importância o mapeamento das áreas de risco.
\end{abstract}

Palavras chave: Precipitação; Deslizamento; Moradias; alagamentos.

\section{Introdução}

A cidade de ilhéus está localizada no domínio morfoclimático de mares de morros, os domínios morfoclimáticos são definidos a partir das características climáticas, botânica pedológica hidrológica e fitogeográfica segundo Ab'saber (1970). O nome mares de morros, está associado a um grande conjunto de morros arredondados formados por um grande processo de erosão, o termo (mar) está associado com a semelhança dos morros a das ondas do mar.

Por conta de seu relevo, tipo de solo e condições pluviométricas as áreas de ocupação irregular em ilhéus no período de chuva forte sofrem com diversas ocorrências de movimentos de massa que podem levar a perda de vidas, danos matérias e mudanças na paisagem. Na maioria das vezes, esses movimentos de massa, que se configuram como declive abaixo, estão associados a bairros cuja ocupação foi realizada sem 
um planejamento prévio e são constituídos na sua maioria por sub moradias construídas em cortes irregulares na vertente, local desmatado e sem saneamento básico adequado, que acabam por agravar ainda mais a situação tornando esses bairros mais vulneráveis a desastres.

O objetivo deste estudo foi realizar o levantamento de risco de risco a movimento de massa e inundação na área de estudo correlacionando, índice de precipitação e frequência de ocorrências destes fenômenos nos bairros do Amparo, Conquista e Teotônio Vilela, com vistas a contribuir para elaboração de políticas públicas que visem melhorar a qualidade de vida desses moradores.

\section{Metodologia}

A metodologia da pesquisa foi dividida em três (3) fazes a primeira fase foi realizado levantamento e analise documental em gabinete, na segunda fase realizamos o trabalho de campo com visitas aos bairros Conquista, Amparo e Teotônio Vilela (Figura 1), nos quais foram preenchidas as fichas de observação para caracterizar as área e correlacionar com o índice de precipitação, visando a identificação do grau de ricos de ocupação dos bairros citados. Por fim, foi feito o tratamento dos dados qualiquantitativo. A seguir detalhamos um pouco os procedimentos da pesquisa.

As encostas foram observadas e analisadas segundo os seguintes aspectos descritos por FRANCO (2008.) clima, geologia, relevo, solo, vegetação e ação antrópica. A interferência da ação antrópica, ou seja, o que a população residente no local faz para retardar ou avançar os processos erosivos nas encostas.

Para a confecção dos mapas e modelos digitais foi utilizado o software ArcGIS 10.0®. O primeiro procedimento metodológico consistiu na delimitação da área urbana de Ilhéus, através do aplicativo Arc Map, do referido software. O mapa de localização foi gerado a partir de dados disponibilizados no ano de 2010 pela prefeitura municipal de Ilhéus e pela Superintendência de Estudos Econômicos e Sociais da Bahia (SEI Bahia). Para analise foram utilizados ainda o Modelo Digital de Elevação do Terreno (MDT) o mapa de declividade, seguindo a metodologia proposta no Manual para Levantamento Utilitário do Meio Físico e Classificação de Terras no Sistema de Capacidade de Uso, de Lepsch et al.(1991), segundo SILIBILA (2014). O centro da cidade de ilhéus apresenta maior densidade de colinas e morros comparados com as zonas sul e oeste da cidade. O município de Ilhéus localiza-se na região sul da Bahia e faz parte da microrregião Ilhéus-Itabuna.Está na foz dos Rios Cachoeira e Almada, principais bacias hidrográficas regionais e encontra-se a uma distância de aproximadamente $462 \mathrm{~km}$ da capital do Estado, Salvador. 


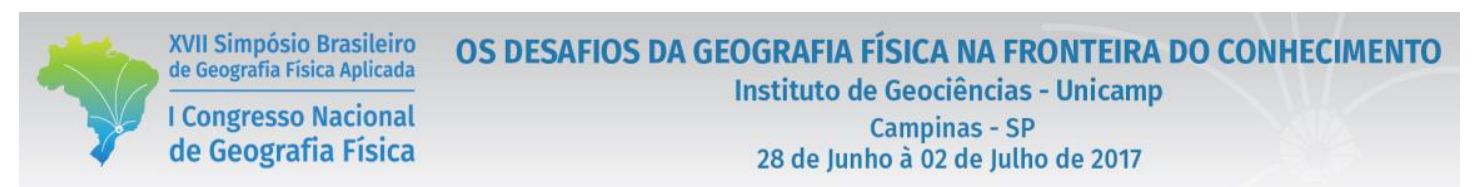

Segundo IBGE (2010), a população de Ilhéus estima-se em 184.231 habitantes, sendo que a população urbana representa aproximadamente $75 \%$ desse total.

\section{Mapa de localização da área de estudo}

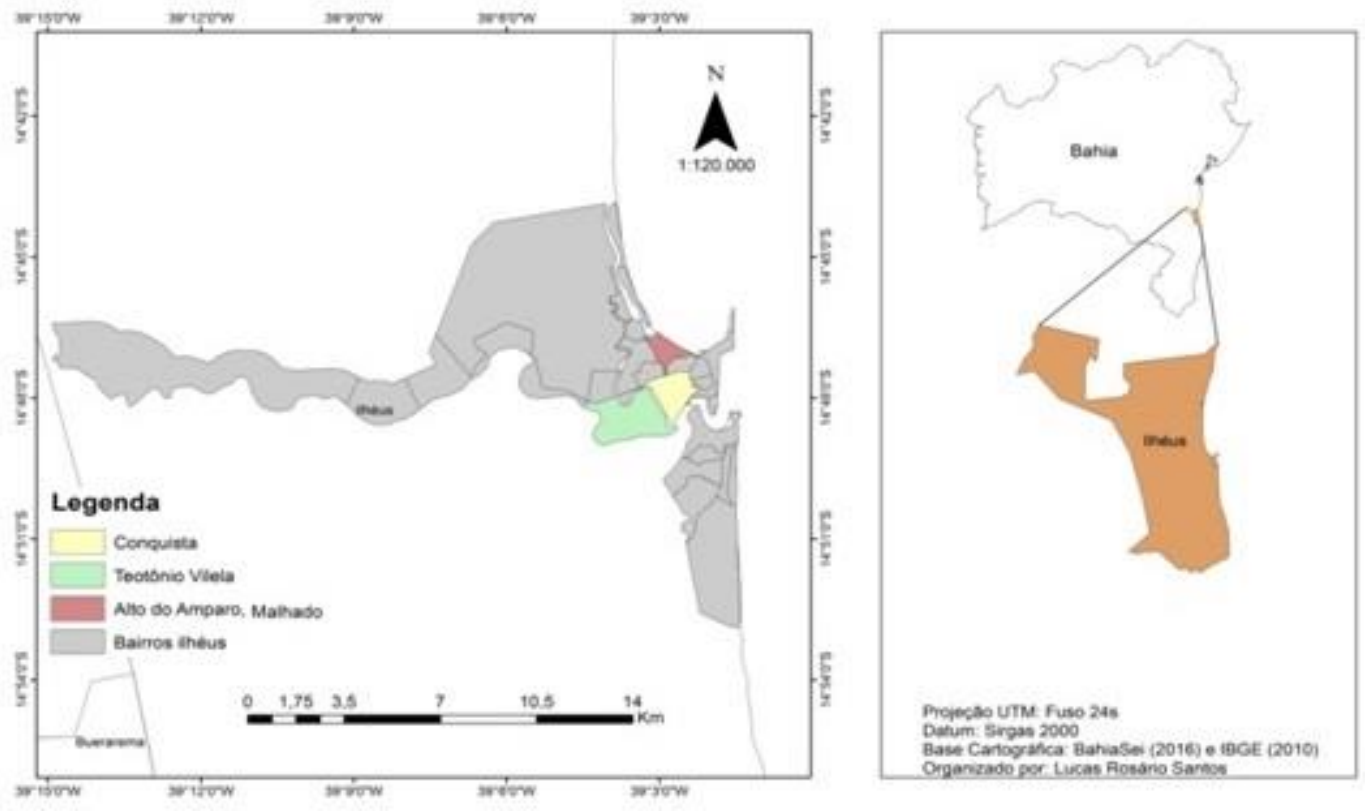

Figura 1 - Mapa de localização da área de estudo

Os bairros citados a cima apresentam áreas de risco devido a interferência antrópica e a alta declividade do terreno, no Conquista o risco é baixo devido a presença de vegetação na encosta, no Teotônio vilela foi observado o corte abrupto no morro que já possui cicatrizes de escorregamentos anteriores assim como no Alto do Amparo que alem de cicatrizes de escorregamentos foi possível observar rachaduras nas casas, postes inclinados entulho na encosta e canos com vazamentos o que torna esse bairro de alto risco a novos deslizamentos.

\section{Refencial teórico}

O referencial teórico básico para a pesquisa foram os trabalhos de BRASIL (1981), IBGE (1995), Ross (1996), Andrade (2003), Franco (2008), Nunes (2015) Casseti (2005), Araujo (2012), além de artigos e trabalhos científicos publicados em revistas e eventos.

Os desastres naturais acontecem em todo o mundo, mas na maioria das vezes estão associados á pobreza, pessoas de baixa renda estão mais vulneráveis porque as elites ocupam as melhores condições topográficas por possuir mais recursos e informações os pobre e marginalizados ocupam as piores condições topográficas e ficam sujeitos a enchentes e a movimento de massa, Segundo (Nunes 2015 apud 
La red 1993) uma vez que as cidades agregam população e atividades, qualquer impacto tem potencial de afetar grande números de pessoas, em especial onde a urbanização se opera de forma célere e associada a elevado índice de pobreza, baixos índice de escolaridade, degradação do meio ambiente, falta de infra estrutura básica e políticas publicas ineficientes.

Com isso os desastres naturais são um problema da natureza per se, mas a relação entre o meio natural e a desorganização e desestruturação da sociedade no território. Os movimentos de massa fazem parte da dinâmica do planeta e são naturais ocasionados pela ação da gravidade associado a precipitação mas por fatores antrópicos acabam ocorrendo com grande frequência nos centro urbanos, Segundo Nunes ( 2015), movimento de massa acontecem quando a tensão de cisalhamento (força que promove os movimentos nas encostas) é excedida, de modo que material intemperizado ou não e conduzido abaixo, envolvendo massas de solo e, eventualmente material rochoso.

Antes dos movimentos de massa acontecer é possível identificar os sinais na paisagem como rachaduras nas casas, postes inclinados e trincas no solo diante desses sinais e recomendado a desocupação imediata do local, pois estes sinais indicam o grau de risco aos movimentos de massa. Segundo Guerra (1966), os deslizamentos são, assim como os processos de intemperismo e erosão, fenômenos naturais contínuos de dinâmica externa, que modelam a paisagem da superfície terrestre.

\section{Resultados e discussões}

A cidade de ilhéus esta localizada no domínio morfoclimático de mares de morros. Estes domínios morfoclimáticos são definidos a partir das características climáticas, botânica, pedológica, hidrológica e fitogeográfica segundo Absaber (1970). O nome mares de morros, esta associado a um grande conjunto de morros arredondados formados por um grande processo de erosão, o termo (mar) esta associado com a semelhança dos morros a das ondas do mar. Estas características aliadas a ocupação irregular do território tornam as áreas de encostas mais vulneráveis a ocorrência de movimento de massa que podem ocasionar perdas de vidas humanas e danos matérias como os já ocorridos na cidade de Ilhéus.

Segundo (Franco 2008 p. 70)

O tipo climático que atua sobre o modelado do clima de Ilhéus é classificado como quente e predominantemente úmido, com temperatura média anual superior a $24^{\circ} \mathrm{C} \mathrm{e}$ média do mês mais frio (junho) superior a $21^{\circ} \mathrm{C}$. Os totais pluviométricos anuais são superiores a $1.900 \mathrm{~mm}$ bem distribuídos pelos diferentes meses do ano, sendo que o período de dezembro a março contém os meses mais chuvosos (variando de 144,9 a $195,2 \mathrm{~mm}$ ), enquanto setembro e outubro são os meses menos chuvosos, com 71,8 e 99,1 $\mathrm{mm}$. 


\section{OS DESAFIOS DA GEOGRAFIA FÍSICA NA FRONTEIRA DO CONHECIMENTO \\ Instituto de Geociências - Unicamp \\ Campinas - SP \\ 28 de Junho à 02 de Julho de 2017}

Sendo assim, nos meses que há maior precipitação dezembro a março com média mensal de ate 154,7mm, a população de ilhéus fica em alerta, segundo a defesa civil da cidade que monitora as áreas de risco e fazem levantamento periódicos das ocorrências de movimentos de massa e inundação na cidade, pois segundo relatos de funcionários do órgão em noticiários de TV e rádio da cidade com $45 \mathrm{~mm}$ de chuva já é possível a ocorrência de movimentos de massa (vide Tabela I).

Tabela I - Índice pluviométrico em (mm) dos últimos sete anos, (vs) média mensal, (vs) total por ano

\begin{tabular}{cccccccccccccc}
\hline & Jan & Fev & Mar & Abr & Mai & Jun & Jul & Ago & Set & Out & Nov & Dez & $\begin{array}{c}\text { Acumulo } \\
\text { Total }\end{array}$ \\
\hline 2009 & $\mathrm{x}$ & $\mathrm{x}$ & $\mathrm{x}$ & 13 & 214 & 32 & $\mathrm{x}$ & $\mathrm{x}$ & $\mathrm{x}$ & $1027^{*}$ & $\mathrm{x}$ & $\mathrm{x}$ & 2.066 \\
2010 & $\mathrm{x}$ & $\mathrm{x}$ & $\mathrm{x}$ & 27 & 94 & 34 & 240 & 77 & 116 & 94 & 73 & 25 & 780 \\
2011 & 91 & 148 & 265 & 385 & 79 & 61 & 177 & 84 & 41 & 0 & 121 & 114 & 1578 \\
2012 & 93 & 151 & 46 & 0 & 0 & 38 & 105 & 281 & 45 & 126 & 132 & 25 & 1077 \\
2013 & 189 & 233 & 52 & $\mathrm{x}$ & 25 & 234 & 113 & 139 & 163 & 123 & 423 & 75 & 1769 \\
2014 & 260 & 172 & 266 & 46 & 92 & 203 & 290 & 51 & 100 & 70 & 204 & 39 & 1793 \\
2015 & 71 & 115 & 74 & 47 & 119 & 464 & 158 & 167 & $7 *$ & $\mathrm{x}$ & $\mathrm{x}$ & $\mathrm{x}$ & 1222 \\
\hline $\begin{array}{l}\text { Média } \\
\text { mensal }\end{array}$ & 140 & 163 & 140 & 103 & 103 & 152 & 180 & 133 & 78 & 288 & 190 & 55 & \\
\hline FONTE: INMET (2009 a 2015), Coordenadoria de Defesa Civil, (2016). Elaborado pelo autor, (2017).
\end{tabular}

O levantamento de dados pluviométricos foi necessário para a correlação com as informações obtidas através da Defesa Civil do município e do Corpo de Bombeiros. O quadro 1, nos mostra que 100\% das ocorrências sejam elas relacionadas aos movimentos de massa ou a áreas inundadas se deram no meses de novembro e dezembro dos anos de 2013 e 2014 escolhidos aqui para esta correlação (figura 2a e 2b).

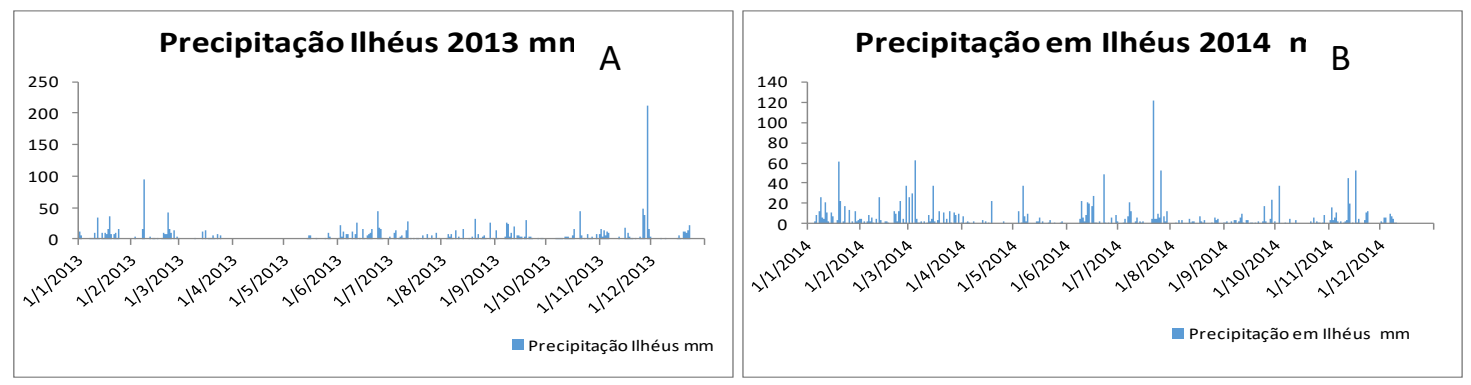

Figura 2 - Precipitação mensal: A)2013; B) 2014.

Fonte: INEMT, 2016. Elaborado pelos autores, 2017. 
As áreas descritas como de riscos em Ilhéus estão associadas com as características físicas do clima, relevo e solos principalmente. Assim como, a precipitação o tipo de solo tem grande influência neste processo, e são caracterizados nestes bairros como latossolo e argissolo.

Segundo Franco (2008, p. 73), o tipo mais comum na área da pesquisa é o Argissolo, que tende a acumular argila por iluviação. Isso pode se constituir em obstáculo para a infiltração da água ao longo do perfil, diminuindo a permeabilidade e favorecendo o escoamento superficial. A sua suscetibilidade aos movimentos de massa tem relação direta com as descontinuidades texturais ao longo do perfil. Já o latossolo, caracterizado por um avançado estágio de intemperização, formado por argila de baixa atividade, boa agregação e pouca acumulação, são solos profundos, bastante porosos e permeáveis. Os latossolos, de um modo geral, apresentam reduzida suscetibilidade aos movimentos de massa, pois tem uma boa permeabilidade e drenabilidade e baixa relação textural, isso garante na maioria dos casos uma boa resistência à erosão. As encostas apresentam boa estabilidade, mas por conta da ocupação do espaço pelo homem, desmatamento, cortes abruptos do terreno, interferência na drenagem natural, esgotamento inadequado etc. Esses fatores contribuem de forma decisiva para rebaixar o nível de estabilidade das encostas. A relação entre essas características naturais do município de Ilhéus geram consequências desastrosas (vide Tabela 2) nas as áreas de encostas, pois o principal agente desencadeador dos movimentos gravitacionais de massa, como os deslizamentos, quedas, e corridas de massas por exemplo, é a água. Portanto, o grande índice de precipitação, conforme mostrado na tabela 1 e na figura 2 , é o responsável pela maioria absoluta das ocorrências relacionados aos deslizamentos nas encostas, é eminente salientar que existe uma relação profunda entre a pluviosidade e os movimentos de massa, pois quanto maior a intensidade das chuvas, maior o risco de movimentos de massa. Segundo Pisani (1998), a água atua na desestabilização das encostas elevando o grau de saturação do solo e consequentemente diminuindo sua resistência, e gerando o escoamento superficial e diversos tipos de erosão (laminar, em sulcos e boçorocas) que aumentam a instabilidade nas encostas.

Os bairros Amparo, Conquista e Teotônio Vilela, tem seus taludes ocupados por uma população baixa renda na sua maioria, cujas características como carência de infraestrutura básica, com moradias de baixo padrão construtivo e que não seguem as normas urbanísticas estabelecidas pelo plano diretor do município. As consequiências estão descritas no quadro 1, a seguir.

Tabela 2: Principais ocorrências de movimentos de massa e/ou inundações registradas entre os anos de 2013 e 2014.

\begin{tabular}{ccc}
\hline Data & Local do deslizamento & Damos socioeconômico \\
\hline $29 / 11 / 2013$ & Alagamento Rua Principal 507 T. & Barranco no fundo da residência com \\
Vilela & perigo de desabamento
\end{tabular}




\begin{tabular}{|c|c|c|}
\hline \multirow{2}{*}{$\begin{array}{l}\text { XVII Simpósio Brasileiro } \\
\text { de Geografia Fisica Aplicada } \\
\text { I Congresso Nacional } \\
\text { de Geografia Fisica }\end{array}$} & \multirow{2}{*}{\multicolumn{2}{|c|}{$\begin{array}{l}\text { OS DESAFIOS DA GEOGRAFIA FISICA NA FRONTEIRA DO CONHECIMENTO } \\
\text { Instituto de Geociências - Unicamp } \\
\text { Campinas - SP } \\
28 \text { de Junho à } 02 \text { de Julho de } 2017\end{array}$}} \\
\hline & & \\
\hline $29 / 11 / 2013$ & $\begin{array}{l}\text { Deslizamento de solo Rua São } \\
\text { José, } 121 \text { A. do Amparo. }\end{array}$ & $\begin{array}{l}\text { Barranco no fundo da residência com } \\
\text { perigo de desabamento }\end{array}$ \\
\hline $29 / 11 / 2013$ & $\begin{array}{l}\text { Deslizamento de solo Rua São } \\
\text { José, } 02\end{array}$ & Deslizamento de solo \\
\hline $04 / 12 / 2013$ & $\begin{array}{l}\text { Deslizamento de solo Av. Belmonte } \\
\quad 347 \text { Conquista. }\end{array}$ & Não houve danos \\
\hline $04 / 12 / 2013$ & $\begin{array}{l}\text { Deslizamento de solo Rua São José } \\
03 \text { Alto do Amparo Malhado }\end{array}$ & $\begin{array}{l}\text { Risco de desabamento imóvel pois o } \\
\text { mesmo se encontra próximo a uma } \\
\text { depressão com aprox. } 70^{\circ}\end{array}$ \\
\hline $05 / 12 / 2013$ & $\begin{array}{l}\text { Deslizamento de solo Rua } 2 \text { de } \\
\text { Julho, s/n - Alto Amparo. }\end{array}$ & Deslizamento de solo fundo da residência \\
\hline $05 / 12 / 2013$ & $\begin{array}{c}\text { Alagamento Rua Primavera, } 212 \\
\text { Teotônio Vilela }\end{array}$ & Deslizamento de solo fundo da residência \\
\hline $05 / 12 / 2013$ & $\begin{array}{l}\text { Deslizamento de solo Rua São } \\
\text { José, } 610 \text { - Alto do Amparo - } \\
\text { Malhado }\end{array}$ & $\begin{array}{l}\text { Imóvel em risco de desabamento } \\
\text { (deslizamento de solo) }\end{array}$ \\
\hline $22 / 07 / 2014$ & $\begin{array}{l}\text { Deslizamento de massa e } \\
\text { alagamento Rua Belo Horizonte } \\
\text { Teotônio vilela. }\end{array}$ & $\begin{array}{l}\text { Perda de bens matérias alagamento em } \\
\text { toda a residência na via de acesso para } \\
\text { rodos os imóveis da rua }\end{array}$ \\
\hline $06 / 12 / 2014$ & Av. Itabuna 2 Conquista & Sem danos materiais \\
\hline $06 / 12 / 2014$ & $\begin{array}{c}\text { Deslizamento de solo Rua } 2 \text { de } \\
\text { Julho, } 208 \text { - Alto do Amparo - } \\
\text { Malhado }\end{array}$ & $\begin{array}{l}\text { Deslizamento de solo fundo da residência } \\
\text { perda parcial de moveis }\end{array}$ \\
\hline $06 / 12 / 2014$ & $\begin{array}{l}\text { Deslizamento de solo Rua Artur } \\
\text { Bernardes, } 360 \text { - Conquista. }\end{array}$ & $\begin{array}{l}\text { Deslizamento de solo no fundo da } \\
\text { residência }\end{array}$ \\
\hline $06 / 12 / 2014$ & $\begin{array}{l}\text { Deslizamento de solo Av. } \\
\text { Belmonte } 21 \text { Conquista }\end{array}$ & Sem danos \\
\hline $06 / 12 / 2014$ & $\begin{array}{l}\text { Deslizamento de solo Rua } 2 \text { de } \\
\text { Julho, } 828 \text { - Alto do Amparo - } \\
\text { Malhado. }\end{array}$ & Sem danos \\
\hline $06 / 12 / 2014$ & $\begin{array}{l}\text { Deslizamento de solo Rua São José, } \\
853 \text { conquista. }\end{array}$ & Sem danos \\
\hline $06 / 12 / 2014$ & $\begin{array}{l}\text { Deslizamento de solo Alto do } \\
\text { Amparo - Malhado. }\end{array}$ & Sem danos \\
\hline $28 / 11 / 2014$ & $\begin{array}{l}\text { Deslizamento de solo Rua São José, } \\
485 \text { - Alto do Amparo Malhado. }\end{array}$ & Não houve danos \\
\hline $28 / 11 / 2014$ & $\begin{array}{c}\text { Alagamento Rua Caixa. } \\
\text { Econômica, } 92 \text { - Teotônio Vilela. }\end{array}$ & Via alagados moradores ilhados \\
\hline $29 / 11 / 2014$ & $\begin{array}{l}\text { Deslizamento de solo Rua São José, } \\
231 \text { - Gamboa - Conquista. }\end{array}$ & $\begin{array}{l}\text { Parte da calçada de acesso destruída } \\
\text { interdição do imóvel }\end{array}$ \\
\hline $29 / 11 / 2014$ & $\begin{array}{l}\text { Deslizamento de solo Rua São José, } \\
141 \text { - Alto do Amparo - }\end{array}$ & Não houve danos \\
\hline $29 / 11 / 2014$ & $\begin{array}{l}\text { Deslizamento de solo Alto do } \\
\text { Amparo, } 811 \text { malhado. }\end{array}$ & Não houve danos \\
\hline
\end{tabular}




\begin{tabular}{|c|c|c|c|}
\hline \multirow{2}{*}{\multicolumn{2}{|c|}{$\begin{array}{l}\text { XVII Simpósio Brasileiro } \\
\text { de Geografia Fisica Aplicada } \\
\text { I Congresso Nacional } \\
\text { de Geografia Física }\end{array}$}} & \multirow{2}{*}{\multicolumn{2}{|c|}{$\begin{array}{l}\text { OS DESAFIOS DA GEOGRAFIA FISICA NA FRONTEIRA DO CONHECIMENTO } \\
\text { Instituto de Geociências - Unicamp } \\
\text { Campinas - SP } \\
28 \text { de Junho à } 02 \text { de Julho de } 2017\end{array}$}} \\
\hline & & & \\
\hline $29 / 11 / 2014$ & $\begin{array}{l}\text { Deslizam } \\
\text { do mei }\end{array}$ & $\begin{array}{l}\text { ento de solo Rua Velosa } \\
\text { io, } 177-(8106-4761)\end{array}$ & $\begin{array}{l}\text { Rachaduras de parede comprometimento } \\
\text { da estrutura do imóvel. }\end{array}$ \\
\hline 29/11/2014 & Deslizam & $\begin{array}{l}\text { nto Rua São José, } 135 \text { A. } \\
\text { do Amparo. }\end{array}$ & Sem danos materiais \\
\hline $29 / 11 / 2014$ & $\begin{array}{r}\text { Deslizar } \\
\text { Espera }\end{array}$ & 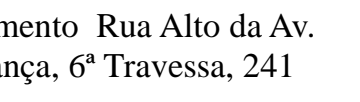 & Sem danos materiais \\
\hline $29 / 11 / 2014$ & $\begin{array}{r}\text { Deslizi } \\
\text { Rena }\end{array}$ & $\begin{array}{l}\text { amento de massa Rua } \\
\text { iscer, } 45 \text { Conquista. }\end{array}$ & Sem danos matérias \\
\hline $29 / 11 / 2014$ & $\begin{array}{l}\text { Deslizam } \\
\text { José, } 132\end{array}$ & $\begin{array}{l}\text { hento de massa Rua São } \\
\text { A. do Amparo Malhado. }\end{array}$ & $\begin{array}{l}\text { Rachaduras de paredes sem danos } \\
\text { materiais }\end{array}$ \\
\hline $29 / 11 / 2014$ & Alagame & $\begin{array}{l}\text { nto Av. Principal, } 618 \text { - } \\
\text { Teotônio Vilela. }\end{array}$ & $\begin{array}{l}\text { Parte da via principal de acesso obstruída } \\
\text { interdição do transito. }\end{array}$ \\
\hline
\end{tabular}

Fonte: Polícia militar, coordenadoria de operações bombeiros militares. $5^{\circ}$ grupamento de Bombeiro Militar, (IMENET.GOV), Coordenação municipal de Defesa Civil (COMDEC).

O que também pode ser observado trabalho de campo é que o homem, por falta de esclarecimento, desencadeia os processos erosivos nas encostas, tornando-se assim o maior indutor da ocorrência de movimentos de massa. Nas áreas estudadas identificou-se como ações antrópicas que intensificam os processos erosivos: cortes excessivos para a implantação de edificações (Figura 3); execução de aterros sem o devido cuidado técnico, apresentando altura e declividade dos taludes incompatíveis com a resistência do solo e com as pressões neutras devidas a fluxos interno de água; retirada da cobertura vegetal e da camada de raízes que auxiliam na estabilidade de taludes (figura 4); concentração de água no solo exposto, ocasionado infiltração e erosões; lançamento rede de esgoto em vários pontos da encosta, ocasionando infiltração constante (figura 5); redes de água com técnicas precárias, ocasionando vazamento e infiltrações; existência de sumidouros; execução de obras de drenagem e estabilização feitas sem nenhuma técnica adequada construtiva convenientes, com materiais e formas inadequadas ou a ausência de qualquer tipo de obra de drenagem, provocando o escoamento superficial da água das chuvas, ocasionando os ravinamentos e boçorocamentos.



Figura 3: Área de risco na AV Belmonte, no bairro conquista em Ilhéus. 


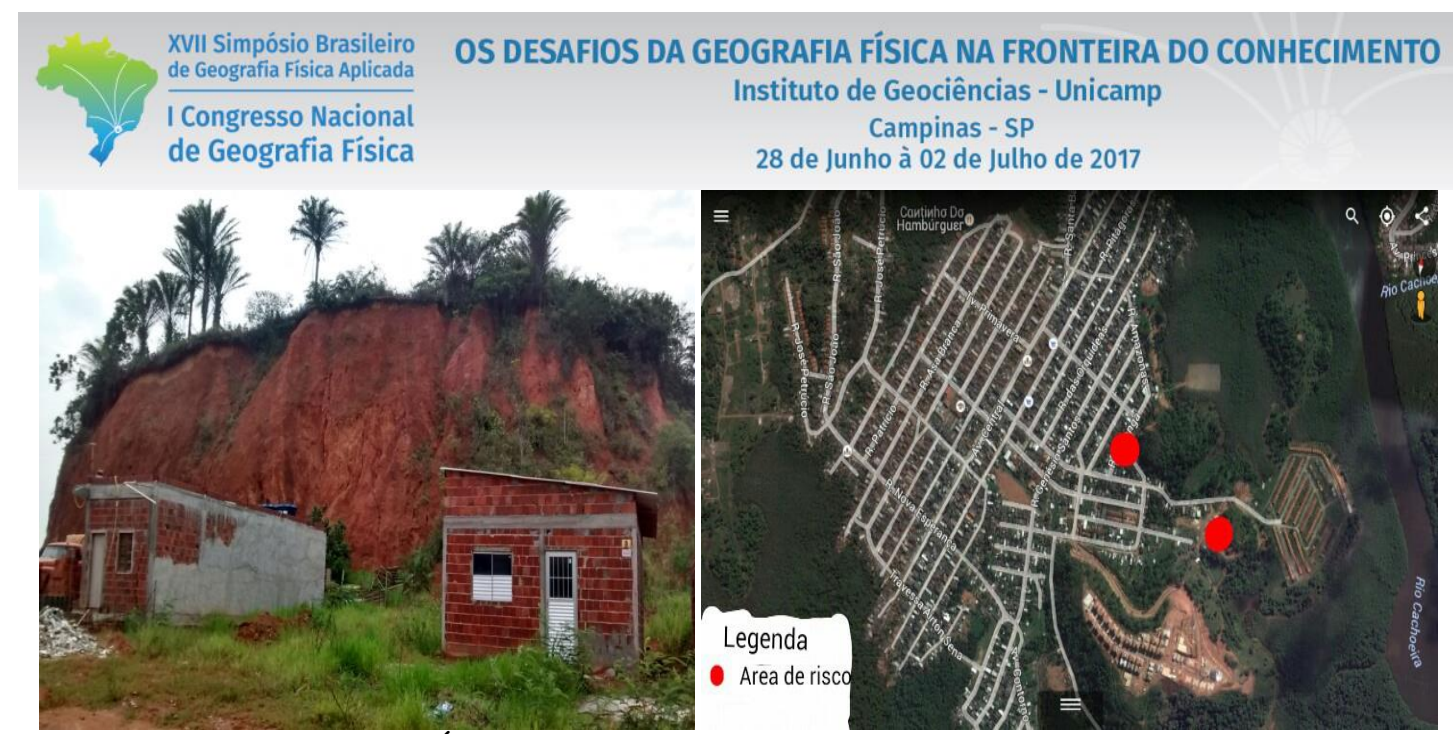

Figura 4: Área de risco Rua. Barro vermelho teotonio vilela.



Figura 5: Área de risco rua 2 de julho alto do amparo, malhado.

As consequências dos movimentos de massa, são caracterizadas como impactos ambientais, ou seja, são as alterações das propriedades físicas, químicas e biológicas do meio ambiente, causadas por qualquer forma matéria ou energia, resultante de causas naturais ou humanas. Os movimentos de massa em Ilhéus, originam impactos ambientais como os mostrados acima, ocasionando acidentes em vários bairros, apresentando, na maioria das vezes vítimas e danos econômicos para a população residente.

\section{Conclusão}

As características naturais detectadas na área de estudo, possuem uma correlação com os movimentos de massa e áreas de riscos identificadas, elas foram analisadas de acordo com: o relevo, o tipo de solo, vegetação existente e os índices pluviométricos.

As relações entre essas características naturais e a área urbana de Ilhéus tem gerado consequências desastrosas nas as áreas de encostas ocupadas, pois o principal agente desencadeador dos impactos ambientais, como deslizamentos e as inundações é a água. Portanto, o grande índice de precipitação aliado 


\section{OS DESAFIOS DA GEOGRAFIA FÍSICA NA FRONTEIRA DO CONHECIMENTO \\ Instituto de Geociências - Unicamp \\ Campinas - SP \\ 28 de Junho à 02 de Julho de 2017}

a declividade das encostas e o material de origem dos solos se configura como responsáveis naturais pelas ocorrências de movimentos de massa nas áreas de encosta, ocupadas por submoradias, e que são agravadas nestes casos pela ocupação desordenada. O que torna o quadro mais grave é ausência de um planejamento habitacional, que transforme essas áreas de encosta sujeitas a eminente de ocorrência de movimentos de massa, que podem provocar desde grandes impactos ambientais até ocasionar perdas de vidas humanas.

\section{Agradecimentos}

À Fundação de Amparo a Pesquisa do Estado da Bahia (FAPESB) pelo financiamento da pesquisa.

\section{Bibliografia}

ANDRADE, M. P. Ilhéus: passado e presente. 2. ed. Ilhéus, Bahia. Editus: 2003.

ARAUJO, I. C. B. Zoneamento Ambiental do município de Ilhéus - BA: uma análise sistêmica. 2012. n. 167, 99 f. Dissertação (Mestrado em Geografia) - Instituto de Geociências, Universidade Estadual de Campinas, Campinas, 2012.

BRASIL. Ministério das Minas e Energia. Secretaria Geral. Projeto RADAMBRASIL Folha SD. 24 Salvador: geologia, geomorfologia, pedologia, vegetação e uso potencial da terra. Rio de Janeiro: MME/SG/ Projeto RADAM BRASIL, 1981. (Levantamento de Recursos Naturais, 24).

CASSETI, V. Geomorfologia. 2005. Disponível em: http://www.funape.org.br/geomorfologia/ Acesso em: 03 fev. 2017.

FRANCO, G. . Risco a escorregamento de encostas do sítio urbano de Ilhéus (BA) como contribuição ao planejamento urbano. 2008. UESC, Ilhéus, BA: 1 CD-ROM Dissertação (Mestrado) - Universidade Estadual de Santa Cruz. Programa Regional de Pós-graduação em Desenvolvimento e Meio Ambiente.

GUERRA, A. J. T.; CUNHA, S. B. Geomorfologia e meio ambiente. Rio de Janeiro: Bertrand Brasil, 1996. 394p.

IBGE. Manual técnico de Geomorfologia. Manuais Técnicos em Geociências. Rio de Janeiro: IBGE, 1995. nº 5

NUNES, L. H. Urbanização e desastres naturais / Lucí Hidalgo Nunes. -- São Paulo : Oficina de Textos, 2015.

PISSANI M. A. J. Áreas de risco (associado a escorregamento) para a ocupação urbana: detecção e monitoramento com o auxilio de dados de sensoriamento remoto / M.A.J. Pissani, W Zmitrovicz - São Paulo : EPUSP 1998.

ROSS, J. L. S. Geomorfologia: ambiente e planejamento. 3. ed. São Paulo: Contexto, 1996.

SOARES, PÓVOAS, H. S.; FONTES, E. O.; MOREAU, A. M. S. Mapeamento geomorfológico da área urbana de Ilhéus, Bahia. Imprensa da Universidade de Coimbra; RISCOS - Associação Portuguesa de Riscos, Prevenção e Segurança. Disponível em: URI:http://hdl.handle.net/10316.2/34837 acesso em: 10-Mar-2017 17:37:54. 